DOI: $10.14451 / 2.123 .58$

\title{
МОДЕЛЬ ЖИЗНЕННОГО ЦИКЛА ВИРТУАЛЬНОЙ ОРГАНИЗАЦИИ
}

\author{
(c) 2018 Хромов Иван Евгеньевич \\ кандидат экономических наук, старший научный сотрудник \\ Центральный экономико-математический институт РАН \\ 117418 , г. Москва, Нахимовский проспект, 47 \\ E-mail:khromov_gaugn@mail.ru
}

В настоящее время развивается концепция виртуальной организации как новой организационной формы управления предприятиями. Все виртуальные организации обычно проходят через четыре стадии своего жизненного цикла. В данной работе описана модель жизненного цикла виртуальных организаций.

Ключевые слова: виртуальная организация, организационная структура, партнёрство, сокращение издержек, управление предприятием, проекты, жизненный цикл, идентификация, формирование, распад, фазы жизненного цикла, модель жизненного цикла.

Тенденции развития современных рынков (глобализация рынков, растущее значение качества товара, его цены и степени удовлетворения потребителей, повышение важности устойчивых отношений с потребителями и заказчиками, растущее значение степени применения новых информационных и коммуникационных технологий) в большей степени повлияли на развитие новых организационных форм управления предприятием.

Одной из таких форм является виртуальная организация - это временное объединение независимых компаний, связанных при помощи информационных технологий для обмена навыками, затратами и доступом к рынкам друг друга. У виртуальной организации зачастую нет ни центрального офиса, ни иерархии, ни вертикальной интеграции. Данное словосочетание часто используют для определения предприятий, действующих на виртуальных рынках и в сети Интернет.

Виртуальные организации проходят через четыре стадии в течение их жизненного цикла. Модель данного цикла виртуальной организации представлена на рисунке 1

Жизненный цикл организации состоит из следующих фаз: идентификации, формирования, производства и распада. Каждая из этих фаз состоит из двух или более основных процессов принятия решений. Этап идентификации включает в себя выявление и оценку возможностей, и их выбор. Эти процессы принятия решений последовательно связаны между собой. Возможности, выявленные в ходе процесса идентификации, служат в качестве исходных данных для процессов оценки и отбора. Фаза идентификации заканчивается, когда отобраны лучшие из имеющихся рыночных возможностей, а информация, связанная с отобранными возможностями, является исходной для фазы формирования.

Основные процессы принятия решений на этапе формирования включают в себя идентификацию партнера, оценку партнеров и их выбор, а также формирование партнерства. Как и в первой фазе жизненного цикла организации, процессы принятия решений на этапе формирования являются последовательно связанными между собой. В процессе выявления партнера, в качестве входных данных, используется информация, полученная на фазе идентификации. На базе этой информации организация получает набор потенциальных партнеров, информация о которых затем используется для процесса оценки и отбора партнеров. Процесс формирования партнерства предполагает фактическое преобразование этих выбранных фирм в виртуальную организацию. После того, как организация была сформирована, она может начинать свою фазу производства.

Фаза производства обычно включает в себя такие основные процессы, как дизайн, маркетинг, финансовый менеджмент, производство и распределение товара. В отличие от фаз идентификации и формирования, на этом этапе процессы не связаны между собой последовательно. Как правило, этот этап наиболее сложен для управления, так как для этого процесса необходима вся информация, связанная с возможностями рынка и внешних партнеров по альянсу, собранная в результате первых двух этапов. Со- 


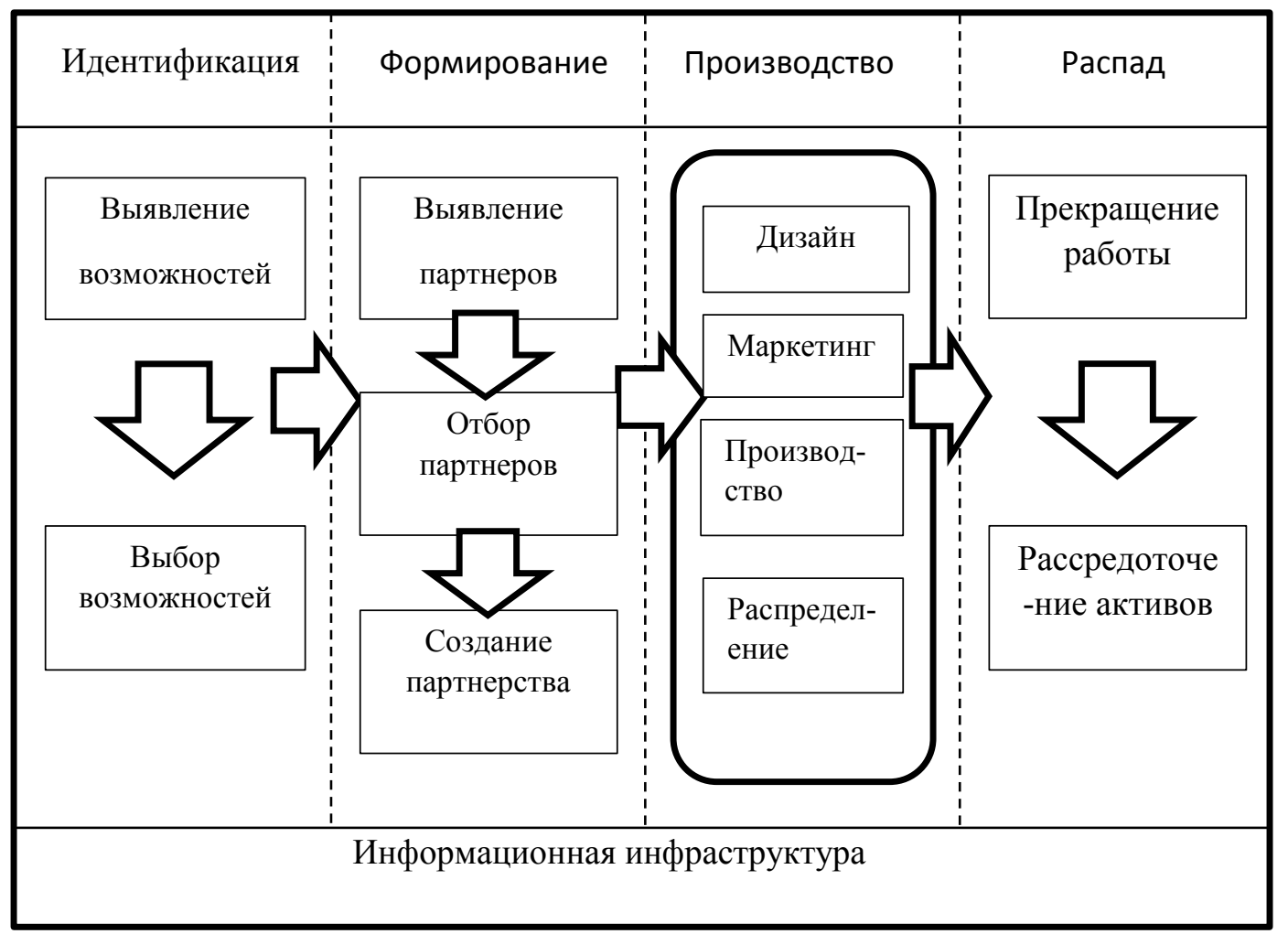

Puc. 1. Модель жизненного цикла виртуальной организации

бранная на данном этапе информация представляет собой итог всей деятельности и всех видов сделок, которые имели место во время работы виртуальной организации. Фаза производства заканчивается, когда рыночные возможности подходят к концу. Как только это произошло, начинается фаза распада.

Основные процессы принятия решений на этапе прекращения деятельности организации включают в себя прекращение работы и рассредоточение активов. Как и в первых двух фазах, эти процессы последовательно связаны между собой. Текущая оперативная информация, такая как уровни запасов, заказы, которые не были завершены является исходной для процесса завершения деятельности. После этого начинается процесс рассредоточения активов. Для этого процесса требуется вся бухгалтерская и юридическая информация, необходимая для завершения всех контрактов и рассредоточения любых партнерских активов между фирмами организации. После завершения этой фазы, фирмы могут свободно формировать другие партнерства. По сути, завершение этого этапа означает «смерть» виртуальной организации, так заканчивается её цикл.

Для описания жизненного цикла вирту- альной организации, приведем пример виртуальной организации, образованной для производства и распространения горнолыжной экипировки. Компания «Обермайер» (Sport Obermeyer, Ltd), основанная в Аспен, штат Колорадо, является одним из ведущих производителей одежды для горнолыжного спорта. Спрос в этой отрасли в значительной степени зависит от целого ряда факторов, которые трудно предсказать - например, погодные условия, модные тенденции, экономика - причем пик розничных продаж сезона составляет всего два месяца в году. Это отрасль, где такая форма управления, как виртуальная организация, может быть использована для формирования распределительных сетей и для быстрой реакции на изменение спроса на продукты с коротким жизненным циклом.

На рисунке 2а изображена идентификационная фаза виртуальной организации, когда «Обермайер» оценивает фирмы с точки зрения их потенциальной интеграции в их распределительную сеть.

Следующие два рисунка описывают виртуальную организацию после того, как она была сформирована и начала функционировать. В первом случае, «Обермайер» выбирает «Лендс 
Рис. 2a

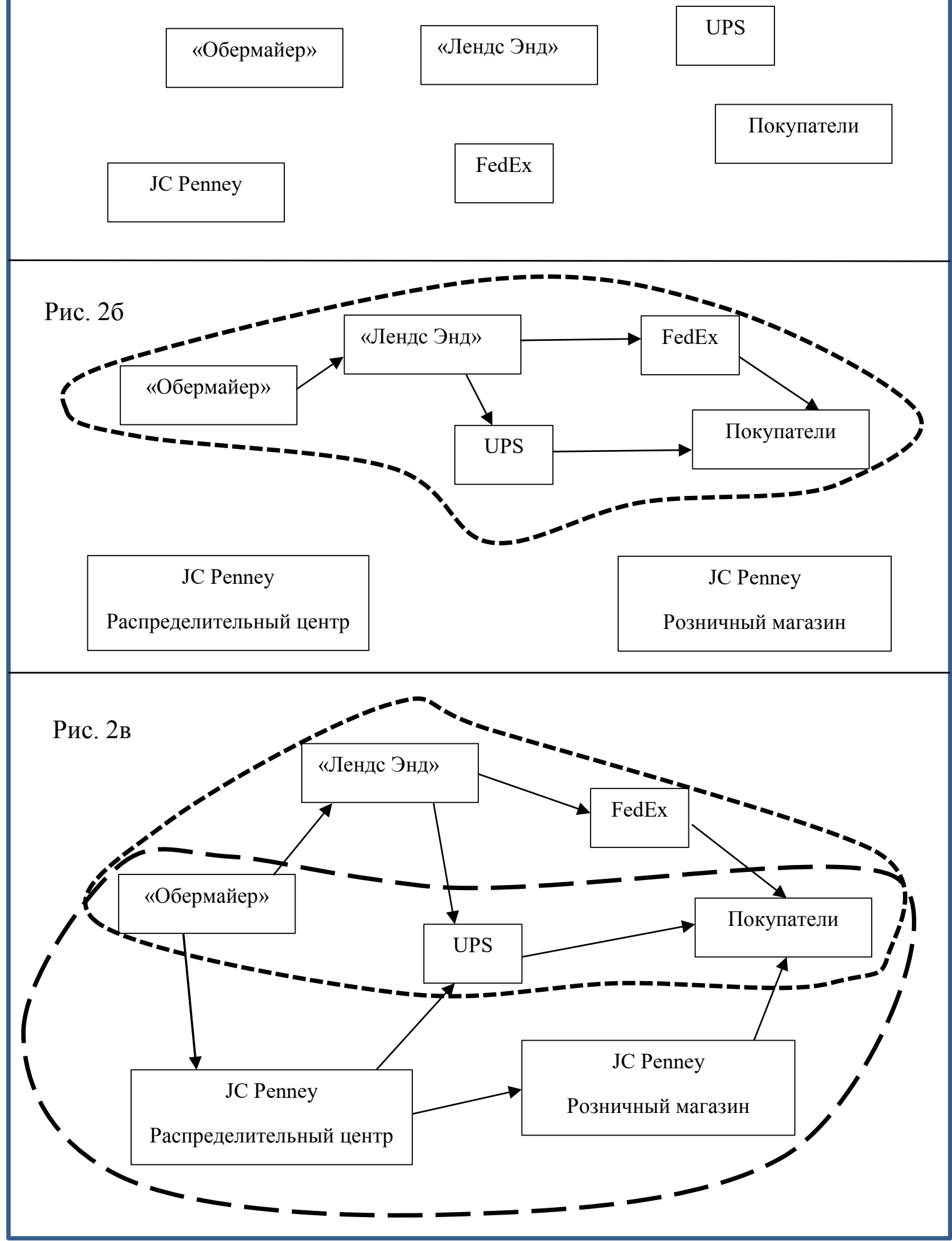

Puc. 2. Жизненный цикл компании «Обермайер» (Sport Obermeyer, Ltd) 
Энд» (Lands' End) в качестве своей торговой точки, принимающей заказы дистанционно и поставляющей заказанные товары по почте. «Лендс Энд», в свою очередь, использует «FedEx Express» (американская грузовая авиакомпания) и UPS (United Parcel Service, Inc.) - компания, специализирующаяся на экспресс-доставке и логистике) для доставки заказанных товаров клиентам. Эта виртуальная организация описана на рисунке 26.

Во втором случае, «Обермайер» выбирает J.C. Penney - сеть американских супермаркетов среднего класса - для розничной продажи своей экипировки. Горнолыжная одежда поставляется в распределительные центры, которые, в свою очередь, распределяют её либо через UPS для продажи по каталогу, либо через свои розничные магазины. Этот случай описан на рис. 2в.

Таким образом, в этом примере, «Обермайер» и UPS являются частью двух виртуальных организаций. В действительности, такие компании, как FedEx входят во многие виртуальные партнерские отношения. Их выбирают потому, что они более компетентны в распределении товаров, чем розничные торговцы, к тому же существуют информационные технологии, позволяющие эффективно координировать отгрузку заказов. В течение всего жизненного цикла продукта, «Обермайер» может динамически регулировать свою дистрибьюторскую сеть по мере изменения потребностей. В заключение, после того, как сезон для розничных продаж горнолыжной экипировки подошел к концу, фирмы могут прекратить свое партнерство и продолжить свой постоянный поиск новых партнеров, как было показано на рисунке 2а.

Поддержание широкого круга процессов принятия решений необходимо, чтобы обеспечить эффективное управление виртуальной организации в течение всего жизненного цикла организации. Поэтому необходима поддерживающая их информационная инфраструктура, позволяющая необходимой информации быть доступной для быстрого и точного управления.

\section{Библиографический список}

1. Fisher M. L., Hammond J.H., Obermeyer W.R., Raman A. Making supply meet demand in an uncertain world, Harvard Business Review, May-June 1994.

2. Jägers H., Jansen W., Steenbakkers W. Characteristics of Virtual Organizations. Organizational Virtualness, Proceedings of the VoNet, 1998, April 27-28.

3. Strader T. J., Lin F.R., Shaw, M.J. Information infrastructure for electronic virtual organization management. Decision Support Systems, 1998, № 23, p. 75-94. 